\title{
Organizações empresariais e ação política no Brasil a partir dos anos 80
}

Denise B. Gros ${ }^{1}$

\begin{abstract}
Democracia econômica é uma das muitas expressões que não passam de tolices populares - no caso, uma contradição em termos - mas que são utilizadas para justificar maior intervenção estatal na economia, cujos resultados são lesões à liberdade individual e ao direito de propriedade, além de menor eficiência no uso de recursos escassos. (...) a grande maioria dos problemas econômicos pode ser resolvida via mercado, na base de decisões individuais. E o processo de mercado é sabidamente mais eficiente, mais eficaz, mais efetivo do que o processo político. (IL Notícias 6, maio 1992).
\end{abstract}

A citação acima, retirada de um boletim mensal divulgado pelos Institutos Liberais, reflete uma das tendências que se encontra no universo das organizações empresariais no Brasil das últimas décadas. Esse universo é bastante complexo e heterogêneo, pois inclui organizações de natureza e objetivos muito diferenciados. Existem organizações empresariais para defesa de interesses econômicos ou corporativos, como os sindicatos, federações e associações setoriais, bem como organizações de defesa de interesses políticos, as quais variam de matizes mais

1 Doutora em Ciências Sociais (Unicamp), pesquisadora da Fundação de Economia e Estatística (FEE/RS). E-mail: gros@fee.tche.br

Civitas, v. 3, n 2, jul.-dez. 2003, p. 273-300 
conservadores como os Institutos Liberais até organizações progressistas como o Instituto Ethos. A partir dos anos 90, esse panorama já repleto de colorações adquiriu novas nuances com o crescimento do número de organizações mantidas por grandes empresas para desenvolver projetos que auxiliem na diminuição dos problemas sociais do país: as Fundações dedicadas à ação social, que constituem o chamado Terceiro Setor. Esta nova tendência no meio empresarial ainda está por ser melhor estudada e não será tratada neste texto.

O período da vida política brasileira que se iniciou com a Nova República tem sido uma conjuntura política extremamente interessante para a análise das organizações políticas mantidas por empresários. Boa parte delas surgiu ou se fortaleceu no período da Assembléia Nacional Constituinte, para fazer frente às forças populares nela representadas. Entre as organizações surgidas nesse período, algumas tiveram vida efêmera como a UBE (União Brasileira de Empresários), outras duraram mais tempo, como o PNBE (Pensamento Nacional das Bases Empresariais), e outras ainda, vêm atuando desde então, com características muito peculiares. É o caso do Instituto Liberal, organização criada por empresários no início dos anos 80 para atuar como um think tank ideológico ${ }^{2}$ entre as elites brasileiras.

Como centros de difusão ideológica do neoliberalismo, os Institutos Liberais se constituem numa forma peculiar de organização de determinadas frações empresariais da burguesia brasileira, cuja trajetória de inserção corporativista no Estado teve grande relevância na sua constituição histórica. Diferentemente das organizações corporativas, que negociam diretamente com o Estado os interesses da burguesia, ou das associações setoriais, que defendem interesses econômicos espe-

${ }^{2}$ Os think tanks são instituições presentes no processo de formulação de políticas públicas nos Estados Unidos e na Inglaterra desde os anos 40 (Denham, 1996). Esses institutos de pesquisa produzem conhecimento sobre os temas sujeitos à regulamentação pública e principalmente, formulam projetos de políticas públicas orientados pela doutrina do neoliberalismo. Em geral, são institutos privados de pesquisa e debate sobre teoria econômica e políticas públicas; têm uma equipe técnica de alto nível ou contratam consultores; e divulgam o resultado dessas pesquisas através de livros, periódicos e publicações em geral, e de participação em debates nos meios universitários, na mídia e nos órgãos de assessoria técnica dos partidos políticos (Hollings, 1993). Recentemente, vários autores têm demonstrado como os conservadores norte-americanos conduziram uma guerra de posição muito bem sucedida nos últimos trinta anos contra o Welfare State e todas as conquistas sociais, dos trabalhadores, das minorias etc., através da ação de uma rede de think tanks financiados por doações generosas de fundações mantidas pelas grandes empresas (Domhoff, 1979; Davis, 1981; Nash, 1996; Stefancic e Delgado, 1996; Usseem, 1979; Vogel, 1983; Weaver, 1989). Nesse processo, os conservadores conseguiram não só garantir a vitória de Reagan como definir políticas públicas conservadoras nas áreas de educação, previdência social, direito das minorias étnicas etc. O mesmo ocorreu na Inglaterra com a ação do Institute of Economic Affairs e do Adam Smith Institute, think tanks da Nova Direita que contribuíram para a vitória de Thatcher e o desmonte do Estado de BemEstar Social naquele país (Cockett, 1995; Denham, 1996). 
cíficos de setores industriais ou financeiros frente ao Estado, os Institutos Liberais se constituem como entidades civis que tomam como eixo central de sua atividade a ideologia, a difusão de uma concepção de mundo entre os segmentos dominantes da sociedade. Aqui não se trata de defender interesses econômicos imediatos e sim, da tentativa de construir uma hegemonia burguesa, de difundir o neoliberalismo como uma concepção de mundo que transforme os preceitos do livre mercado em "pensamento único".

A doutrina neoliberal constituiu-se em fundamento de políticas públicas e configurou-se como ideologia hegemônica no Ocidente a partir do final dos anos 70 e, sobretudo, durante os 80 , quando foi posta em prática pelos governos Thatcher na Grã-Bretanha e Reagan nos EUA. Além desses casos, quase todos os países da Europa Ocidental tiveram governos de direita que adotaram as reformas liberais nesse período. Mas, foi na América Latina que ocorreu a "primeira experiência neoliberal sistemática do mundo" (Anderson, 1995, p. 19). Inspirado em Hayek, Friedman e na Escola de Chicago, o Chile conseguiu, durante a ditadura, de 1973 a 1989, aplicar o receituário liberal em toda a sua extensão: desregulamentação, desemprego, repressão sindical, "redistribuição" de renda em favor dos ricos e privatização dos bens públicos.

Contudo, o pensamento neoliberal não surgiu nos anos 70, ele se originou nos debates econômicos europeus do início do século XX. Segundo os representantes da Escola Austríaca de Economia, especialmente Friederich Hayek, a crise era conseqüência do excessivo poder do movimento operário, pois as reivindicações salariais e de gastos sociais feitas pelos sindicatos teriam comprometido a acumulação capitalista. A solução, para os liberais, estava em medidas como a estabilidade monetária, a diminuição dos gastos sociais e a restauração da taxa de desemprego, para assim enfraquecer a capacidade de reivindicação dos trabalhadores e, por fim, quebrar o poder dos sindicatos. As idéias lançadas pelos liberais nessa época permaneceram no nível da teoria por várias décadas, até a crise dos anos 70 e a recessão no mundo capitalista avançado.

Ainda que só tenha conseguido ser uma doutrina vitoriosa nos anos 80, o pensamento neoliberal desenvolveu-se como um movimento ideológico internacional desde os anos 30, liderado entre outros por Hayek e pela Sociedade Mont Pelerin, criada em 1947 para reunir intelectuais e políticos liberais do mundo todo. A doutrina tem como sua obra emblemática o livro $O$ caminho da servidão, escrito por Hayek em 1944 como uma crítica ao socialismo e a todas as formas de planejamento econômico. O movimento ideológico desenvolveu-se através da formação de redes de intelectuais, acadêmicos, políticos, institutos de pesquisa, publicações 
liberais e da mídia, em especial nos Estados Unidos e na Grã-Bretanha, bem como da existência de fundações e empresas dispostas a financiar todas essas instituições. A existência dessas redes foi fundamental para a consolidação do liberalismo como alternativa política, para a vitória de Margareth Thatcher na Inglaterra e de Ronald Reagan nos Estados Unidos, no final dos anos 70, e para a internacionalização o movimento, nos anos 80. O elo brasileiro desta rede é representado pelos Institutos Liberais. ${ }^{3}$

Criados por um grupo de grandes empresários em 1983, e transformados em rede nacional depois da instauração da Nova República, com sedes no Rio de Janeiro, São Paulo, Brasília, Curitiba, Porto Alegre, Belo Horizonte, Salvador e Recife, os Institutos Liberais são sustentados por alguns dos maiores grupos econômicos nacionais e estrangeiros em operação no país e dedicam-se à atividade política e ideológica de divulgação dos valores do neoliberalismo. Para atingir esse objetivo, desenvolvem um trabalho de dupla natureza: doutrinação ideológica entre as elites brasileiras, especialmente aqueles segmentos considerados formadores de opinião - universitários, jornalísticos, políticos, militares, jurídicos e intelectuais em geral; e formulação de estudos e propostas de projetos de políticas públicas de cunho liberal.

Para entender o contexto em que surgiram os Institutos Liberais apresentamos, num primeiro momento, uma análise da conjuntura política que se apresentava nos anos 80 no Brasil e as mudanças que ocorreram nas formas de organização e participação política do empresariado brasileiro desde então. A seguir, apresentamos sinteticamente algumas estratégias de ação e propostas de políticas públicas do Instituto Liberal que justificam nossa hipótese de que ele representa uma organização política peculiar no universo das instituições de representação de interesses do empresariado brasileiro.

\section{Formas de organização política do empresariado brasileiro nos anos 80}

No Brasil, a década de 80 foi marcada pela crise e o esgotamento do modelo de desenvolvimento baseado na forte presença do Estado. Para conter o acelerado processo inflacionário, a política econômica de estabilização implementada na Nova República adotou várias medidas extraordinárias, como o congelamento de preços e salários implantado pelos planos Cruzado I e II, em 1986 e Plano Bresser em 1987;

\footnotetext{
${ }^{3}$ A discussão sobre o movimento neoliberal como parte da rearticulação das forças conservadoras internacionais nas últimas décadas e o surgimento e atuação dos Institutos Liberais no Brasil foi desenvolvida na tese de doutorado defendida na Unicamp, em 2002: Institutos Liberais e neoliberalismo no Brasil da Nova República (Gros, 2003).
} 
a abertura externa, a desregulamentação e a privatização promovidas pelos planos Collor I, em 1990, e Collor II, em 1991; e, finalmente, a reforma monetária do Plano Real em 1994. Dessa forma, as medidas econômicas implementadas a partir dos anos 80 , e especialmente na década de 90, aproximaram a economia brasileira ao modelo neoliberal - desregulamentação das forças concorrenciais, abertura comercial, privatização de empresas estatais, e reformulações dos aparatos administrativo, previdenciário e fiscal.

Os anos 80 também se caracterizaram pelo processo de transição política e os conseqüentes esforços de consolidação da ordem democrática. A ação conjunta desses fatores engendrou transformações significativas na vida política nacional. Ao longo da década de 80 , a sociedade brasileira passou por uma grande politização que se materializou na organização e mobilização das diferentes forças sociais do país e na luta política que se desenvolveu através da Campanha das Diretas, em 1984; da eleição indireta de Tancredo Neves; da instauração da Nova República, em 1985; das eleições para a Constituinte, em 1986; do debate que se travou no Congresso Constituinte até a promulgação da nova Carta, em 1988; da campanha para a Presidência da República, em 1989; do impeachment de Collor, em 1992; da eleição de Fernando Henrique Cardoso, em 1994; para citar apenas os fatos políticos mais abrangentes.

Esses episódios compuseram o início do processo de institucionalização de novas regras do jogo político que, praticamente restrito ao Executivo durante os governos militares, transbordou para toda a sociedade com a redemocratização. $\mathrm{O}$ Congresso, os partidos, os meios de comunicação de massa e as instituições da sociedade civil passaram a participar ativamente da vida política nacional.

A ampliação da arena política decorrente desse processo impôs a todas as forças sociais a necessidade de se organizar para defender seus interesses frente à sociedade política revigorada, especialmente na conjuntura da Constituinte, na qual diferentes projetos de desenvolvimento estavam em disputa. As lutas dos trabalhadores em anos anteriores já haviam evidenciado a importância crescente do movimento sindical e de suas organizações de cúpula, em especial a Central Única dos Trabalhadores (CUT) e o Partido dos Trabalhadores (PT). A esfera partidária também cresceu em importância com a recuperação do Congresso Nacional como arena de luta e negociação política no país.

A organização dos trabalhadores e a ampliação da arena política, somadas aos efeitos da crise econômica, colocaram para as diferentes frações do empresariado brasileiro a necessidade de renovar e ampliar suas formas de organização e de ação frente às demais forças sociais e ao Estado. De fato, a mobilização política dos 
empresários foi intensa e incluiu a utilização de todos os meios de participação a seu dispor, desde o incremento da atuação direta na política, como deputados, senadores e ministros, passando pela renovação de lideranças nas entidades corporativas e a intensificação do uso de lobbies, até a criação de novas organizações para a defesa de seus interesses políticos. Isso porque a nova configuração política do país apresentou situações para as quais os mecanismos de representação corporativa ou setorial, utilizados pelo empresariado brasileiro durante os governos autoritários dos anos 70 , não se mostravam mais adequados. ${ }^{4}$

Para entender as transformações que foram ocorrendo nas formas de ação política utilizadas pelos empresários brasileiros nas últimas décadas, é necessário fazer um recuo no tempo. Como se sabe, o sistema político-institucional de relacionamento entre as classes, vigente no Brasil desde os anos 30, foi baseado no corporativismo, ${ }^{5}$ um sistema de representação de interesses compatível com diferentes tipos de regimes; um arranjo institucional para articular interesses que são organizados em associações envolvendo a sociedade civil e as estruturas decisórias do Estado (Schmitter, 1974).

Nesse modelo, o Estado controla os conflitos sociais através da subordinação das estruturas de representação de interesses de trabalhadores e empresários, perdendo os partidos a sua função de canalizadores das demandas da sociedade para a esfera política (Diniz, 1978). No Brasil, a fragilidade do sistema de partidos permitiu a emergência de um estilo tecnocrático de governo e a permanência das práticas de inserção direta de interesses no Estado, própria da etapa corporativista

${ }^{4}$ Nesse estudo privilegiamos a análise da ação das organizações empresariais de natureza política. As mudanças na estrutura de representação de interesses econômicos dos empresários brasileiros, sobretudo da indústria, para adaptar-se às reformas direcionadas à abertura do mercado nos anos 90 são abordadas em profundidade nos trabalhos recentes de Eli Diniz e Renato Boschi (2002).

5 "O corporativismo pode ser definido como um sistema de representação de interesses no qual as unidades são organizadas num número limitado de categorias singulares, de pertencimento compulsório, não competitivas, ordenadas hierarquicamente e diferenciadas funcionalmente, e que são reconhecidas ou autorizadas (quando não criadas pelo Estado, que lhes confere monopólio de representação de suas respectivas categorias), em troca da observância de algum controle na seleção de líderes e na articulação de apoios e demandas" (Schmitter, 1974, p. 93, tradução de Almeida, 1996, p. 134). Schmitter (1974) definiu dois sub-tipos de corporativismo para explicar a existência do fenômeno em países tão diferentes quanto a Suécia, a Grécia, Portugal, o Brasil etc.- o corporativismo societário ou neocorporativismo e o corporativismo de Estado. O corporativismo estatal é um sistema de representação de interesses subordinado à autoridade estatal ou mesmo criado por ela. Esse tipo de corporativismo seria o elemento definidor, ou mesmo uma necessidade estrutural, do capitalismo "atrasado", anti-liberal, neomercantilista, cujo Estado é autoritário. Em contrapartida, o corporativismo societário nasce da dinâmica da sociedade civil e tem relativa autonomia em relação ao Estado. Este tipo de corporativismo seria um componente intrínseco ao capitalismo avançado, pós - liberal, democrático, organizado, e cujo Estado define-se como de bem-estar social (Schmitter, 1974, p. 105). 
que se iniciou com o Varguismo (Camargo e Diniz, 1989). Isso se comprova claramente no pós-64, com a associação do corporativismo ao autoritarismo do Estado e das classes dominantes, aprofundando-se um tipo de representação corporativa socialmente assimétrica que, ao garantir um acesso especial dos empresários aos centros decisórios, acentuou os privilégios desses setores em relação aos demais (Rua, 1990; Diniz, 1978).

Além disso, devido às características do Estado autoritário dos anos 60 e à inexistência de uma organização única de cúpula do empresariado, que permitisse a negociação de questões políticas e econômicas gerais, aprofundou-se também uma forma setorizada de relação do empresariado com os organismos estatais. Isto porque o Estado autoritário era forte e centralizador quanto à definição da política econômica, mas descentralizador quanto à aplicação dessa mesma política, que era pulverizada entre os diferentes ministérios, agências de financiamento e conselhos econômicos (Martins, 1978). Nesse contexto, a relação estabelecida entre o Estado e o empresariado desenvolvia-se através de múltiplos canais de acesso às diferentes instâncias de regulação econômica. Esses canais incluíam contatos institucionais estabelecidos através das organizações corporativas de empresários (como as Federações de Indústria e Comércio), e os "anéis burocráticos" (Cardoso, 1975), alianças que se estabeleciam entre representantes do setor privado e os burocratas responsáveis pelas agências setoriais do Estado, criando vínculos clientelísticos com o objetivo de traduzir os interesses específicos em políticas concretas. Nos meios acadêmicos do país existe um relativo consenso em torno da idéia de que existe uma tendência do empresariado brasileiro a desfrutar "apoliticamente" do acesso ao aparato de estado através de contatos pessoas e de anéis burocráticos, em vez de organizar-se politicamente para buscar, pela via partidária e com apoio popular, o controle explícito das políticas de Estado.

Para defender seus interesses frente a esse Estado centralizador, burocratizado, mas com definição setorializada das políticas econômicas, o empresariado brasileiro desenvolveu diferentes formas de representação e de negociação de interesses. Por um lado, os empresários mantiveram suas organizações corporativas (sindicatos, federações e confederações nacionais) criadas nos anos 30 e reguladas pelo Ministério do Trabalho. Por outro lado, especialmente a partir da segunda metade dos anos 70, os empresários criaram organizações extra-corporativas de âmbito nacional, associações civis independentes da regulação do estado, com o objetivo de representar e negociar os interesses de cada setor diretamente com as agências regulatórias da política econômica setorial (Diniz e Boschi, 1979). AAssociação Brasileira da Indústria de Base (ABDIB) e a Associação Nacional de Fabri- 
cantes de Veículos Automotores (Anfavea) são apenas dois exemplos entre muitas outras associações criadas para representar os interesses dos diferentes segmentos do setor industrial. Nos anos 80 , novas associações surgiram também no setor bancário-financeiro, como a Associação Brasileira de Bancos Comerciais e Múltiplos (ABBC) e a Confederação Nacional das Instituições Financeiras (CNF) (Minella, 1988, 1990, 1993). O mesmo ocorreu no setor agrário com a criação da Sociedade Rural Brasileira (SRB), da Organização das Cooperativas Brasileiras (OCB) ou da recente Associação Brasileira de Agribusiness (Rua, 1990). Essas associações proliferaram enormemente desde o final dos anos 60 com a diversificação da estrutura econômica brasileira, e têm sido intensamente utilizadas pelos empresários para negociar com o Estado suas reivindicações econômicas setoriais.

Em contrapartida, as demais forças sociais não tiveram a seu dispor canais de representação de interesses durante o período autoritário, já que não havia liberdade de imprensa, o Congresso e os partidos não tinham qualquer autonomia para representar os interesses das demais classes e os movimentos de trabalhadores eram fortemente reprimidos. Nesse contexto, os empresários utilizavam as federações, associações setoriais e contatos pessoais e clientelísticos como mecanismos de negociação com o Estado. Frente aos trabalhadores, não havia necessidade de criar mecanismos de negociação ou de fazer jogos de dominação política ou ideológica, já que o empresariado não se defrontava com uma classe trabalhadora solidamente organizada e tinha a força do Estado autoritário a seu dispor.

O renascimento do movimento operário e as greves dos metalúrgicos do ABC paulista em 1978 começaram a mudar essa situação. Elas afetaram também o universo patronal, em especial o sistema de representação de interesses empresariais, “(...) ao redefinir o peso relativo das estruturas oficial e privada desse sistema - sindicatos, federações e confederações, de um lado; associações civis, de outro" (Cruz, 1997, p. 350). A proliferação de associações setoriais no pós-64 teria sido paralela ao esvaziamento das federações e confederações. Sem negar a importância adquirida pelas associações como decorrência indireta da diferenciação de interesses e para contornar os limites impostos pela legislação sindical, Cruz considera que essa importância no período deveu-se à desativação do movimento operário, já que os reajustes salariais eram definidos pelo Estado, a repressão policial era grande e as empresas podiam demitir sem ônus. Quando essas condições se alteram no final dos anos 70, o interesse dos empresários pelas federações aumentou, o que se comprova pelas disputas ocorridas nas eleições de suas diretorias, e a renovação de seus quadros. Por um lado, esse movimento de revitalização das federações se deve ao monopólio da representação assegurado às entidades ofici- 
ais junto à Justiça do Trabalho. Mas, por outro lado, tem a ver com uma característica universal da organização de interesses patronais. Ela ocorre para responder a dois tipos de problemas: a) os que resultam da concorrência intercapitalista e, portanto, incidem sobre segmentos específicos do empresariado e coloca-os em oposição uns aos outros, no campo de luta das associações setoriais, por exemplo; b) aqueles que resultam da mobilização e organização dos trabalhadores, os quais afetam "potencialmente o conjunto da classe e estimula(m), nela, a constituição de relações mais abrangentes de reciprocidade" (Cruz, 1997, p. 352).

A relação entre o empresariado e o Estado também começou a mudar a partir de 1974 e muito mais intensamente a partir da Campanha contra a Estatização de 1976, quando importantes setores do empresariado se distanciaram de algumas decisões do regime militar. A política industrializadora do governo Geisel, refletida no II PND, alterou a aliança básica do sistema autoritário: empresas internacionais dedicadas à fabricação de bens duráveis de consumo e importação de equipamentos; setor nacional dependente da internacionalização da produção local e as empresas que inicialmente haviam apoiado o II PND. O setor nacional da indústria pesada dependia em grande medida de apoio estatal, que não pôde se concretizar devido à crise econômica internacional, à pressão estrangeira para vender equipamentos e à dívida externa. Estes contratempos provocaram a politização imediata do setor descontente. Em 1977, alguns empresários começaram a falar em democracia, introduzindo a dimensão política no seu discurso. Houve uma espécie de aproximação aos pontos de vista da oposição: menos intervenção direta do Estado na economia, maior participação na tomada de decisões e demandas retóricas por democracia (Cruz, 1995) Mas essa aproximação não foi inspirada por uma opção democrática. A proposta de política econômica do Governo Geisel, que pretendia gerar uma industrialização autônoma a partir da criação de um setor de bens de capital, provocou a descoberta da democracia pelo empresariado (Cardoso, 1983).

Contudo, o período em que o empresariado pareceu autonomizar-se e difundir um discurso "liberal", no sentido de tentar incrementar o poder político e o controle do Estado pela sociedade civil foi muito breve. Durante o Governo Figueiredo, os empresários tornaram a aliar-se com as soluções políticas impostas pelo Estado, patrocinando a transição controlada desde cima, pela cúpula do regime. Sem dúvida, esta atitude não foi alheia ao contexto muito complexo em que se deu o fim do regime militar, situação que ia além de qualquer cálculo estratégico seguro porque, para os empresários, o que estava em jogo não era "o montante de suas perdas e ganhos, mas sua posição mesma na sociedade" (Cruz 1995, p. 292). Uma grande cota de incerteza rondava o fim da ditadura, o que induziu um salto nas atitudes empresariais que, da mera defesa de interesses concretos, passaram a outras capazes de levar em conta uma multiplicidade de fatores que ultrapassavam seus interesses imediatos. 
Portanto, foi a entrada de outros atores na cena política dos anos finais da ditadura, em especial a aparição de novos antagonistas como os trabalhadores organizados, que contribuiu para determinar o discurso e a prática dos empresários, que neste caso revela uma grande ambigüidade. Enquanto parecia impossível o abandono do Estado para alcançar uma liderança autêntica na sociedade, o discurso proclamava princípios teóricos do liberalismo. Segundo Cardoso, o discurso dos líderes industriais não refletia a proposta de uma nova hegemonia e sim uma identidade abstrata, baseada em assuntos que uniam todos contra o estado, “(...) como se este não expressasse uma dominação que se articula na própria sociedade. Esta identidade ideológica abstrata e geral desaparece, naturalmente, no embate concreto dos interesses" (Cardoso, 1983, p. 23). Com o renascimento do movimento operário e a eclosão das greves a partir de 1978, os empresários voltaram a recorrer ao Estado como escudo protetor. O projeto que contou definitivamente com o respaldo dos empresários foi o do governo, de transição lenta e gradual para a democracia.

A complexidade da situação que se tratou até aqui alude, sem dúvida, à que se coloca a partir dos anos 80 . Com a crise econômica, a redemocratização, a recuperação da importância do Congresso e dos partidos políticos e o fortalecimento das organizações sindicais, ampliaram-se a arena política e os canais de acesso à ela. A negociação política, que se fazia estritamente dentro do aparelho de Estado durante o regime autoritário, passou a incluir o Parlamento e as demais organizações da sociedade. Assim, a transição política recolocou “(...) a questão do poder e da formulação de diretrizes como 'briga em campo aberto', obrigando o empresariado a buscar novas formas de participação na formulação de diretrizes, agora bastante diversas dos costumeiros 'contatos de primeiro grau' com ministros e burocratas do alto escalão” (Dreifuss, 1989, p. 43). Além disso, com a implantação do Congresso Constituinte, onde estariam em confronto as aspirações de todas as forças sociais, deslocou-se para ele a "responsabilidade de articular um pacto que nem os partidos, nem o governo, nem as associações civis nem os empresários e os trabalhadores foram capazes de operacionalizar" (Camargo e Diniz, 1989, p. 13).

Essa mudança substancial na forma de relacionamento entre o Estado e a sociedade deixou duas questões evidentes para as classes dominantes. Por um lado, as tradicionais organizações da estrutura corporativa como as federações empresariais, ou mesmo as mais recentes como as associações setoriais, mantinham um estilo de atuação semelhante à prática sindical, não sendo mais adequadas para o estilo de luta política que se prenunciava na Constituinte. Por outro lado, os partidos conservadores tradicionais também não se adequavam às necessidades dos 
empresários na luta que viria a ser travada no Congresso (Dreifuss, 1989). Essas questões reforçaram a importância das organizações políticas e ideológicas, e obrigaram o empresariado a criar novas formas de participação política ou a renovar as já existentes. Dentre elas, deve-se citar o aumento da participação direta de alguns líderes empresariais em cargos públicos administrativos e executivos e na própria Constituinte; a revitalização das entidades corporativas através da renovação de suas direções; e, principalmente, a criação de organizações com o objetivo específico de mobilização política para o embate na Constituinte, como a União Democrática Ruralista (UDR), a União Brasileira de Empresários (UBE), o Pensamento Nacional das Bases Empresariais (PNBE) e o Instituto de Estudos para o Desenvolvimento Industrial (IEDI) e o Instituto Liberal.

Dentre as novas organizações políticas de empresários surgidas nos anos 80, algumas alcançaram grande visibilidade no período da Constituinte, como a União Democrática Ruralista (UDR) e a União Brasileira de Empresários (UBE). A UDR defendia de forma agressiva os interesses dos grandes proprietários de terra contra as tentativas de reforma agrária e a UBE foi criada para coordenar a atuação das organizações empresariais na Constituinte. Entretanto, entre essas duas entidades, ao menos a UBE parece ter mesmo servido apenas como "unidade tática de luta" (Cruz, 1997; Dreifuss, 1989), pois praticamente desapareceu do cenário político após a Constituinte. Já a UDR manteve-se em atividade na década de 90, com maior ou menor intensidade, para fazer forte oposição ao Movimento dos SemTerra. Em contrapartida, outras organizações de empresários que surgiram no final da década de 80, como o IEDI, o PNBE e o Instituto Liberal, parecem apresentar objetivos de mais longo prazo e formas de ação peculiares.

O Instituto de Estudos para o Desenvolvimento Industrial (IEDI), criado em 1989 em São Paulo, representa alguns dos maiores grupos industriais do país, principalmente da indústria de base. O IEDI foi criado para desenvolver estudos e elaborar propostas alternativas e estratégias de desenvolvimento econômico e social para o Brasil (Diniz e Boschi, 1993), em especial aquelas propostas globais que interessam à grande burguesia industrial (Cruz, 1997). Essas propostas baseiam-se num diagnóstico das transformações da produção industrial a nível mundial e do processo de globalização econômica, para reivindicar ao Estado a definição de uma política industrial de longo prazo. Essa política permitiria aos industriais brasileiros alcançarem a competitividade necessária para se integrarem ao processo de globalização. O IEDI propõe a modernização do aparelho de Estado, a fim de que o Estado possa desempenhar o papel de coordenador estratégico dos rumos do desenvolvimento (IEDI, 1990). 
O Pensamento Nacional das Bases Empresariais (PNBE) surgiu em $1990 \mathrm{em}$ São Paulo, propondo-se a ser "uma entidade formada por empresários para mudar o Brasil pelo exercício da ética e da cidadania" (PNBE. Ideário). O PNBE destacouse na busca de fórmulas mais pragmáticas de negociação entre empresários e trabalhadores. Segundo Diniz e Boschi (1993), a organização foi formada por pequenos e médios empresários que se sentiam alijados das decisões na FIESP. Até 1995, o PNBE tinha núcleos regionais no interior de São Paulo, no Rio de Janeiro e em Brasília.

Os Institutos Liberais surgiram nessa conjuntura mas seu foco não era centrado nos debates da Constituinte, apesar de terem participado das articulações do movimento empresarial da época. Seu projeto era mais ambicioso e de longo prazo: transformar os valores dominantes da sociedade, educando as elites nos princípios do livre-mercado. A seguir, veremos que estratégias são utilizadas para a tentativa de realização desse objetivo.

\section{Os Institutos Liberais: objetivos e estratégias de ação}

O cenário pós-ditadura proporcionou, assim, o ambiente adequado para a atuação do Instituto Liberal como think tank ideológico de frações da burguesia brasileira. A emergência de um sistema híbrido e mais fluido de representação de interesses estabeleceu um espaço próprio para a luta. Nele coexistem elementos corporativistas de Estado, neo-corporativistas e pluralistas, tanto entre o empresariado quanto no campo sindical. A instância constituinte no final dos anos 80 se colocou, assim, como um desafio e uma oportunidade para a convergência de frações do empresariado brasileiro em direção a um projeto neoliberal, confrontado com seus opositores: o PT, o movimento sindical, as burocracias e elites militares e civis desenvolvimentistas e estatistas. Ainda que os empresários tenham conseguido triunfos no campo da definição de direitos e regras essenciais para a economia de mercado, o nacionalismo e os princípios estatistas também tiveram vitórias, em especial no que se refere à definições que afetam as atividades do capital estrangeiro no país, assim como o movimento trabalhador, que conseguiu aprovar algumas de suas principais demandas. Como muitas dessas vitórias ficaram para ser reguladas posteriormente pela legislação ordinária, como é o caso da legislação trabalhista e previdenciária, descortinou-se para a década de 90 um cenário de luta por um projeto hegemônico da burguesia, em contraposição a outros projetos e propostas quanto à linha mais adequada para o desenvolvimento do país.

Os Institutos Liberais se definem como entidades culturais sem fins lucrativos nem vinculações partidárias, abertos a todos os interessados e mantidos por doações de pessoas físicas e jurídicas. Cada Instituto tem uma Diretoria Executiva e um Conselho de Mantenedores, composto de empresários e que se constitui na ins- 
tância máxima de decisão de cada Instituto Liberal. Todos os Institutos obedecem ao mesmo estatuto e são subordinados a um Conselho Nacional, formado pelos presidentes dos institutos estaduais, que define a estratégia de atuação dos Institutos.

Os recursos para a manutenção dos Institutos Liberais vêm de doações de empresas associadas como "mantenedoras" e que incluem alguns dos grandes grupos econômicos nacionais e estrangeiros em operação no país. ${ }^{6}$ Outra parcela vem dos convênios, financiamentos e parcerias com think tanks, fundações e organizações neoliberais estrangeiras que fazem parte da rede internacional neoliberal como o Liberty Fund, a Tinker Foundation, a Atlas Economic Research Foundation e o Center for International Private Enterprise.

A vinculação dos Institutos Liberais do Brasil à essa rede internacional de think tanks neoliberais é fundamental, não apenas por sua integração no movimento ideológico internacional, mas principalmente porque o intercâmbio com entidades liberais estrangeiras propicia a troca de idéias e o aprimoramento dos conhecimentos, assim como o acesso a informações sobre fontes de financiamento e cursos de formação em entidades e universidades estrangeiras. ${ }^{7}$

Apresentando-se como organizações independentes de partidos políticos, os Institutos Liberais definem como seu objetivo fundamental a difusão dos princípios do liberalismo, que consideram os mais eficazes para a promoção do bem-estar moral e material dos indivíduos. De acordo com o credo liberal de Hayek, a noção de liberalismo como a supremacia do indivíduo sobre o Estado é colocada muito claramente: "entendem o liberalismo não como um dogma, mas como um conjunto de princípios capazes de inspirar ações no sentido de mudança social. Esses princípios privilegiam o indivíduo e não o Estado, e defendem a primazia da associação autônoma e voluntária dos cidadãos sobre as formas de organização impostas pelo Estado" (Instituto Liberal, 1993, p. 5).

${ }^{6}$ Entre os grupos econômicos que mantêm os Institutos Liberais estão: Shell do Brasil, Xerox do Brasil, Hoescht do Brasil, Dow Química, Gessy Lever, Nestlé, Carrefour, Mesbla, Grupo Fenícia, Indústrias Villares, Bradesco, Banco de Crédito Nacional, Banco Noroeste, Citibank, e Banco de Boston.

${ }^{7}$ Entre os think tanks que mantêm contatos com os Institutos Liberais estão: Cato Institute, Liberty Fund, International Center for Economic Growth, Center for International Private Enterprise, Tinker Foundation, Reason Foundation, Atlas Economic Research Foundation, Institute for Humane Studies, Foundation for Economic Education, Heritage Foundation, Cascade Policy Institute, Independent Institute, International Center for Economic Growth e Ludwig Von Mises Institute, dos EUA, bem como o Foro Latinoamericano e da Fundación Francisco Marroquin, da Guatemala, a Escuela Superior de Economía y Administración da Argentina e o Instituto Libertad y Democracia, do Peru (IL Notícias, n. 37, 1994; n. 64, 1997). 
Entre esses principios está o direito à liberdade, definida como o fundamento do Estado de Direito que, seguindo à risca o pensamento da Escola Austríaca de Economia, deve garantir, fundamentalmente, a primazia da liberdade econômica sobre as "exigências legais e administrativas discriminatórias", leia-se, a regulamentação e a interferência estatais, sobretudo no campo das relações de trabalho; o reconhecimento da propriedade privada como condição para a liberdade econômica e política; e, fundamentalmente, a supremacia do mercado para dirimir as diferenças e premiar os vitoriosos com o lucro.

A defesa da liberdade econômica, conforme o pensamento de Hayek, pressupõe a primazia da liberdade de mercado sobre o planejamento e a regulação econômica. Isso fica claro no conceito de desenvolvimento econômico que “(...) deverá ser conduzido, no quadro do Estado de direito, pelos indivíduos que produzem riqueza, e não orientado por decisões estatais de caráter econômico e organizatório" (Instituto Liberal, 1993, p. 5).

Desde sua criação no início dos anos 80, os Institutos Liberais divulgam esses princípios através de uma gama bastante variada de atividades de "propaganda" neoliberal, sempre dirigida a públicos selecionados. A forma mais direta de divulgação que utilizam são boletins informativos, geralmente mensais, enviados gratuitamente a associados, mídia, universidades, entidades empresariais etc. Esses boletins, normalmente de quatro páginas, apresentam um editorial sobre algum tema abordado na perspectiva liberal, seja uma questão nacional, seja a reprodução de um artigo publicado em um think tank neoliberal norte-americano como a Heritage Foundation, o Cato Institute e muitos outros. Os boletins publicam ainda notas curtas sobre as atividades e promoções dos Institutos Liberais e da rede internacional de think tank liberais, assim como comentários sobre a política nacional e sobre projetos de lei em tramitação no Congresso. ${ }^{8}$

\section{Publicando a doutrina}

A principal atividade dos Institutos Liberais, em seus primeiros anos de funcionamento, foi a tradução e publicação de livros de pensadores clássicos considerados fundamentais para a compreensão do liberalismo. O objetivo era patrocinar a edição de uma bibliografia acadêmica básica sobre teoria liberal, para se contrapor

\footnotetext{
${ }^{8}$ As informações apresentadas nesse estudo foram coletadas nas seguintes publicações: "IL Notícias", publicado mensalmente desde dezembro de 1991 pelo Conselho Nacional de Institutos Liberais; "Idéia Liberal", publicado de 1988 a 1992 pelo Instituto Liberal de São Paulo e, a partir de 1993, denominado "Informe Liberal"; nos folhetos Idéias Liberais, publicados pelo Instituto Liberal de São Paulo desde 1993; no livrete "1983-1993. Instituto Liberal - Os primeiros dez anos" (Instituto Liberal, 1993); e em livros e demais publicações dos institutos.
} 
ao pensamento marxista dominante nos meios intelectuais e acadêmicos (Idéia Liberal, n. 18, 1989). Inicialmente, foram publicados alguns dos principais livros dos representantes da Escola Austríaca de Economia: A teoria da exploração do socialismo comunismo, de E. Bohm-Bawerk; e as obras de Friederich Hayek : $O$ caminho da servidão; Direito, legislação e liberdade; Desemprego e política monetária e Desestatização do dinheiro. De Ludwig Von Mises foram publicados: As seis lições; Uma crítica ao intervencionismo; A mentalidade anticapitalista; Liberalismo; e A ação humana.

Os Institutos Liberais publicaram também, além dos clássicos, alguns dos autores que foram importantes na consolidação do movimento neoliberal e conservador norte-americano: Eamonn Butler, Frank Knigth, Henry Hazlitt, Ayn Rand, assim como autores mais modernos, vinculados à Escola de Chicago e de Virgínia, como Israel Kirzner, James Buchanam, Murray N. Rothbard, entre outros. Todos eles apresentam análises econômicas ou sociais do ponto de vista neoliberal, sejam versões mais didáticas do pensamento de von Mises e Hayek, sejam análises mais modernas do papel do Estado, e da questão da Economia do Direito ou a crítica às políticas de preservação ambiental como uma violação dos direitos de propriedade. Os Institutos Liberais publicam também autores nacionais que rezam pela cartilha do neoliberalismo.

O trabalho de divulgação mais amplo e permanente dos Institutos Liberais na área de publicações é a série Idéias Liberais, iniciada em 1993, e que já distribuiu mais de cem folhetos em forma de mala-direta. Através dessa série são veiculados textos curtos e didáticos sobre questões teóricas do liberalismo, como o pensamento de Popper ou a teoria austríaca de economia, assim como análises de problemas da realidade brasileira sob o ponto de vista neoliberal.

Desde 1998, os Institutos Liberais vêm editando a revista Think Tank, talvez sua publicação mais elaborada, com um conselho editorial composto por intelectuais liberais que contribuem para várias publicações dos Institutos e um conselho de administração que reúne grandes empresários. O primeiro número da revista trazia na capa o Presidente da República, Fernando Henrique Cardoso, recém eleito, caminhando firme para o futuro, além de um artigo escrito por ele. Com preparação gráfica esmerada e contendo ensaios de intelectuais conservadores reconhecidos internacionalmente, a revista Think Tank publica ainda encartes que apresentam as propostas de políticas públicas dos neoliberais, e outros com versões resumidas de autores liberais clássicos. Com tiragem de 3000 exemplares, Think tank é distribuída entre os associados dos institutos, grandes empresas, autoridades etc. 


\section{Doutrinando públicos estratégicos}

Os Institutos Liberais oferecem periodicamente cursos sobre doutrina liberal preparados especialmente para empresas e ministrados por professores universitários das áreas de filosofia, política e economia (IL Noticias, n. 8, 1992). Para um meio acadêmico e de juristas, os Institutos Liberais organizam, desde 1990, colóquios patrocinados pelo Liberty Fund dos EUA, instituição que desempenha importante papel na rede internacional conservadora, como financiador de pesquisadores de think tanks neoliberais em todo o mundo. Ao proporcionarem aos participantes a oportunidade de debater idéias com especialistas de várias áreas do conhecimento e de várias nacionalidades, esses encontros auxiliam na formação de um corpo técnico capacitado a subsidiar o movimento neoliberal.

Dada a importância que os neoliberais atribuem não só à formulação de políticas públicas e proposição de projetos de leis como também à divulgação da teoria liberal entre aqueles que se dedicam à aplicação dessas leis, o campo jurídico tem sido uma área de atuação privilegiada pelos Institutos Liberais, desde o debate na Constituinte no final dos anos 80. No início dos anos 90, os Institutos Liberais elaboraram uma proposta liberal para a reforma da Constituição brasileira, lançada no documento Diretrizes para a Revisão Constitucional (1993), além de intensificar seus contatos com o meio jurídico: advogados, juizes, professores e alunos das Faculdades de Direito, organizando seminários e debates entre juristas e empresários e com a Ordem dos Advogados do Brasil (OAB).

A elite militar, outro grupo formador de opinião segundo os Institutos Liberais, também mereceu atividades especiais nos anos 90, quando representantes dos institutos ministravam palestras nos cursos de formação de oficiais da Escola de Comando do Estado Maior do Exército, na Escola Superior de Guerra e no Clube Militar (IL Notícias, vários números, 1992-97).

Os meios de comunicação também receberam atenção especial nos anos 90 , quando os Institutos Liberais promoveram o Prêmio Fenícia de Imprensa, patrocinado pelo Grupo Fenícia e concedido, entre 1990 e 1992, aos melhores artigos escritos em defesa da causa liberal; e o programa semanal Rádio Livre, com informações econômicas e entrevistas, transmitido em vários estados do país e patrocinado pelo Unibanco, entre 1990 e 1994.

O Fórum da Liberdade é outra atividade de divulgação do neoliberalismo apoiada pelos Institutos Liberais desde 1988. Promovido pelo Instituto de Estudos 
Empresariais (IEE) ${ }^{9}$ em Porto Alegre, é talvez o evento de maior repercussão pública entre as atividades promovidas pelos defensores do liberalismo no Brasil. Realizados anualmente, os fóruns da Liberdade têm reunido uma média de 1500 pessoas para assistir palestras sobre as perspectivas econômicas e políticas para a América Latina, ecologia e mercado, educação e a preparação para o trabalho, livre comércio, Custo Brasil etc. ${ }^{10}$ Os palestrantes convidados são, em geral, expoentes do mundo neoliberal como a primeira ministra da Nova Zelândia, responsável pelo "saneamento" neoliberal naquele país, ou políticos "convertidos" do Leste Europeu, assim como intelectuais conservadores e autoridades brasileiras.

\section{“Desideologizando" o ensino de economia}

Segundo a avaliação dos Institutos Liberais, o estudo de economia no país no início dos anos 90 ainda era muito influenciado pelas correntes marxista e pelo pensamento centralizador e planejador de Keynes, o que provocou a marginalização do liberalismo nas universidades. Para combater a hegemonia desse pensamento "ideologizado" e propiciar a ampliação do espaço ocupado pela teoria liberal na reflexão acadêmica, os Institutos Liberais patrocinaram atividades conjuntas com universidades. No Rio de Janeiro, o Ibmec e a Universidade Santa Úrsula incluíram entre suas especializações o estudo da Escola Austríaca de Economia, da Economia do Direito e das Leis e também da Economia do Meio-Ambiente (IL Notícias, n. 47, 1995), e vários de seus professores produzem textos que são publicados pelos Institutos Liberais.

Deve-se mencionar, também, o Prêmio Alfred Marshal - Concurso IL/Nestlé de Monografias, concedido aos três melhores trabalhos elaborados por estudantes universitários sobre temas pré-definidos de economia liberal. O prêmio era patrocinado pela Nestlé e foi concedido anualmente, de 1989 a 1997. A comissão julgadora desse concurso era formada por professores das principais universidades de São Paulo (Idéia Liberal, n. 3,1988; Informe Liberal, mar. 1997).

${ }^{9}$ O Fórum da Liberdade é a única atividade aberta ao público que o Instituto de Estudos Empresariais (IEE) promove. Criado por jovens empresários em 1984 em Porto Alegre, o IEE funciona como uma instituição privada, de acesso restrito a empresários indicados pelos seus sócios, desenvolvendo uma série de atividades internas, de estudos e debates, para formação de lideranças defensoras do ideário liberal. O IEE mantém estreita vinculação com o Instituto Liberal do Rio Grande do Sul, principalmente através vários de seus diretores, que fazem parte também da diretoria do IL-RS (Gros, 1993 ).

${ }^{10}$ Os Fóruns da Liberdade são patrocinados por grandes empresas Grupo Gerdau, Nestlé, Ipiranga, Claro Digital, Vonpar, Bank of Boston, Sebrae, Copesul, Ativa, Habitasul, Varig e Petropar. 
Atividades que propiciavam o intercâmbio de idéias e experiências entre empresários e universitários também foram desenvolvidas para divulgar a filosofia do capitalismo e a experiência concreta de gestão de empresas. No início dos anos 90, foram implementados dois programas: "Empresa na Escola" e "Escola na Empresa" com a Faculdade de Economia e Administração de Empresas do Mackenzie, através dos quais o Instituto Liberal de São Paulo promovia, mensalmente, palestras de empresários na universidade e visitas de grupos de alunos à empresa dirigida pelo palestrante. Com a Faculdade Armando Alvares Penteado (FAAP), o Instituto Liberal de São Paulo desenvolveu o projeto "Repensando o Brasil", no qual eram realizadas palestras e debates sobre os problemas atuais do país para professores, jovens empresários e alunos selecionados. (Idéia Liberal, n. 8, 1989).

\section{“Desideologizando" o ensino elementar}

O Instituto Liberal de São Paulo desenvolveu uma atividade muito especial entre 1992 e 1995: a assessoria e capacitação de professores primários da rede pública. Essa atividade foi inspirada no diagnóstico da educação feito pelo Instituto: o ensino público brasileiro estaria passando por uma grave crise, que se evidencia no despreparo dos alunos para enfrentar o mercado de trabalho, no abandono quase total da rede pública, na falta de qualificação dos professores e nos "conteúdos desatualizados e ideologizados" do ensino. Essa situação se refleteria nas empresas, dificultando a formação e o desenvolvimento de seus trabalhadores e, até mesmo, de seus quadros dirigentes (Idéia Liberal, n. 32, 1992).

Para solucionar esses problemas e melhorar a qualidade do ensino, o Instituto Liberal de São Paulo elaborou uma proposta educacional que tinha como pressuposto "afastar-se das ideologias, permitindo um aprendizado livre de dogmas, um pensamento e um agir independentes, aptos a incorporarem uma perspectiva social humanista" (Idéia Liberal, n. 32, 1992). Essa proposta foi desenvolvida através de dois programas: de aperfeiçoamento de professores de primeiro e segundo graus de ensino e de pesquisa e produção de material didático e pedagógico sob novos enfoques. Nos primeiros anos da década de 90, o Instituto Liberal de São Paulo afirma ter reciclado uma parcela significativa dos professores da rede pública do estado de São Paulo.

Ainda na esfera educacional, o Instituto Liberal de São Paulo promoveu campanhas de estímulo à cidadania, entendida como oposta à ação do Estado na regulação econômica e social. Em 1993, o cartunista Maurício de Souza foi contratado para produzir uma cartilha da cidadania em quadrinhos, com a Turma da Mônica. Na cartilha, Mônica e seus amigos explicam de forma didática que todos os 
problemas do país, da inflação às deficiências nos serviços de saúde, previdência, educação etc., se devem à grande ineficiência do Estado brasileiro e à sua excessiva intervenção em todas as áreas da vida nacional. A primeira edição da cartilha $\mathrm{A}$ Turma da Mônica - Cidadania teve uma tiragem de 500 mil exemplares e foi patrocinada pelo Unibanco, Bradesco, Citibank, Metalac e Shopping Eldorado. Foram feitas outras edições patrocinadas por diferentes empresas. A cartilha foi distribuída na rede escolar pública durante a Semana da Cidadania, promovida pelo Instituto Liberal de SP com o apoio de outras instituições em 1993 e repetida em 1994. Na Semana da Cidadania de 1993 foi lançado o Concurso Viver a Cidadania, promoção conjunta do IL-SP, da Secretaria de Educação do Estado de São Paulo, do MEC, do SESI e outras entidades, para premiar os melhores trabalhos sobre a cidadania realizados pelas crianças das escolas que receberam as cartilhas. Esse concurso, sob a coordenação do IL-SP, teve uma edição estadual em 1994 e outra nacional, em 1995 (Informe Liberal, jun. 1995).

Em 1994, com o patrocínio da Siemens, Nestlé e C\&A, o Instituto Liberal de São Paulo lançou outra cartilha: "O Cidadão", de autoria de Jacy de Souza Mendonça (vice-presidente do Instituto Liberal de São Paulo). Nela se explica como é organizada a sociedade brasileira, a divisão de poderes, o tipo de governos, as eleições, enfim, todos os problemas sociais e econômicos do país são atribuídos à má administração do Estado, à corrupção etc. A cartilha propõe a supremacia do mercado como única forma de respeitar os direitos individuais do cidadão. Durante a década de 90, o trabalho do Instituto Liberal de São Paulo nessa área continuou a se realizar através da distribuição das cartilhas para escolas, instituições governamentais e empresas (Informe Liberal, maio 96).

\section{Propondo políticas públicas}

Além da divulgação dos princípios do neoliberalismo entre as elites, a outra atividade privilegiada pelos Institutos Liberais no Brasil desde 1990 é o debate de políticas econômicas e sociais para fundamentar a formulação de propostas de políticas públicas. Alguns desses debates ocorreram em eventos públicos de porte realizados em São Paulo nos anos 90. Os Fóruns Liberais de Políticas Públicas, patrocinados por empresas e organizações da área financeira como a Sogeral, a Companhia de Seguros da Bahia, e a Febraban, entre outras, reuniram empresários, políticos e autoridades da área econômica do Governo, para discutir a política industrial, monetária etc. Em 1992, o I Fórum Liberal da América Latina: O Caminho para uma Economia de Mercado reuniu representantes da Argentina, Chile, México, Venezuela, Colômbia, Panamá, Uruguai e Brasil para discutirem as experiências liberais em curso na América Latina. 
A discussão da reforma do Estado foi o tema de outro grande seminário promovido pelos Institutos Liberais em São Paulo em 1995, o ciclo de palestras "Reinventando o Governo", inspirado no livro homônimo de David Osborne, consultor de políticos nos Estados Unidos que ministrou a palestra inicial. Osborne propõe a introdução da lógica empresarial nos espaços governamentais como orientação para a reforma do governo. O ciclo durou vários meses e contou com a participação de personalidades estrangeiras, autoridades governamentais e representantes de diferentes áreas de políticas públicas: agrícola, financeira, trabalhista, de privatização, tributária e fiscal (Instituto Liberal, 1995).

$\mathrm{Na}$ área de formulação de projetos de políticas públicas de cunho liberal, os Institutos Liberais vêm promovendo a discussão do que poderia se tornar um programa liberal de governo, através do debate dos projetos de lei e medidas provisórias apresentados ao Congresso Nacional e também da formulação de projetos de políticas públicas de cunho neoliberal. Os estudos são encomendados a especialistas e financiados por empresas locais e também por think tanks liberais como a Tinker Foundation, a Atlas Economic Research Foundation e o Center for International Private Enterprise dos EUA. ${ }^{11}$ Um resumo dessas propostas é divulgado através da publicação Notas - Avaliação de Projetos de Lei, com tiragem de cinco mil exemplares e distribuição gratuita para associações de classe, órgãos de imprensa, autoridades governamentais e parlamentares.

Nesses policy papers, os Institutos Liberais analisam projetos de leis em discussão no Executivo ou no Judiciário e formulam propostas de políticas baseadas nos preceitos liberais. Até 2001, foram publicadas mais de 80 edições dessas Notas, discutindo todo tipo de políticas públicas, desde a nova Constituição brasileira, a reforma da legislação trabalhista, até a privatização da Previdência Social. A discussão sobre a legislação trabalhista e as funções sociais do Estado - prestação de serviços de saúde, educação e previdência social - é considerada central para os Institutos Liberais, que empreenderam esforços no sentido de formular proposições de mudança, das quais tratamos a seguir.

\section{A proposta de flexibilização das relações trabalhistas}

Para os neoliberais, o pressuposto de igualdade das partes contratantes para poderem negociar condições de trabalho sem interferências, especialmente do Es-

${ }^{11} \mathrm{O}$ Center for International Private Enterprise dedica-se à promoção internacional dos princípios da democracia e do livre mercado e financia também a realização de policy papers em instituições liberais de outros países da América Latina (IL Notícias1, 1991). 
tado, é elemento fundamental para se atingir a liberalização da economia e a soberania do mercado. Por essa razão, a redefinição da legislação sobre as relações de trabalho é assunto da maior importância no projeto dos Institutos Liberais. As críticas feitas à legislação trabalhista consolidada na CLT de 1943 apresentam argumentos como a sua inadequação ao desenvolvimento da economia e da sociedade brasileiras, além do agravamento dessa inadequação pelos "avanços trabalhistas", conquistados pelos representantes dos trabalhadores na Constituinte e incorporados à Constituição de 1988. Os estudos divulgados pelos Institutos Liberais sobre esse tema enfatizam a necessidade de "liberar" os trabalhadores dos entraves legais que estariam dificultando o livre jogo do mercado e provocando desemprego e aumento da informalidade. Suas propostas de reforma da legislação trabalhista são apresentadas em vários documentos das séries Notas de Políticas Públicas e Idéias Liberais, e também em encartes da revista Think Tank e livros editados pelos Institutos Liberais.

A existência de uma legislação específica para regular as relações de trabalho no pais é radicalmente criticada pelos Institutos Liberais. Em substituição ao Direito do Trabalho, considerado impositivo porque dita às partes o que e como podem contratar, sua proposta é a liberalização das regras do mercado sobre as relações de trabalho, que “(...) devem reger-se pelos mesmos princípios que norteiam os demais campos do Direito, onde todos são iguais perante a lei. A liberdade contratual deve ser restaurada, cabendo à lei dirimir conflitos de direito, e não conflitos de interesses." (Notas, n. 58, p. 1, 1996)

Como forma de agilizar os processos e reduzir os custos dos litígios, os Institutos Liberais propõem a adoção de poucas leis, baseadas numa concepção de Direito de caráter negativo, como é o caso do Direito Civil: eliminar o poder normativo da Justiça do Trabalho como condição essencial para implantar a livre negociação entre trabalhadores e empregadores; extinguir a representação classista na Justiça do Trabalho e substituí-la por órgãos de conciliação e arbitragem sem caráter jurisdicional; e instituir o efeito vinculante nas decisões judiciais, que confere caráter de lei e de decisão judicial para os tribunais inferiores e os juizes de primeira instância (Notas, n. 66, 1997).

Várias análises publicadas pelos Institutos Liberais enfatizam os aspectos derivados das mudanças históricas, sobretudo no que se refere à revolução tecnológica e à adoção de tecnologias poupadoras de mão-de-obra para justificar as propostas de flexibilização da legislação trabalhista. As transformações que essa mudança tecnológica vem impondo sobre a natureza do trabalho e sobre o mercado de trabalho teriam decretado a obsolescência da estrutura legal que regula as relações 
de trabalho no país. Nessa perspectiva, os encargos sociais seriam os responsáveis pela elevação do custo na geração de empregos. Segundo a análise dos Institutos Liberais, à dificuldade representada pela regulamentação da relação de trabalho soma-se a "ideologia do garantismo legal", através da qual se pretende proteger os trabalhadores aumentando os seus direitos tanto na Constituição quanto na CLT. Isto aumentaria o descompasso entre a situação de abertura econômica e o quadro legal extremamente rígido que regula as relações de trabalho. Em um encarte especial sobre relações trabalhista publicado pela revista Think Tank em 1998, os Institutos Liberais defendem com veemência seus princípios e criticam o modelo estatal intervencionista, que funcionaria, segundo sua visão, como uma semente do totalitarismo. O desafio, para os neoliberais, seria a superação dos princípios que ainda estão impregnados na mentalidade dos opositores da modernização das relações trabalhistas e a implantação de um modelo não intervencionista.

\section{A proposta de privatização das funções sociais do Estado}

Ainda que reconheçam a gravidade dos problemas sociais do país, os Institutos Liberais não admitem a adoção de políticas públicas baseadas no critério redistributivista do gasto social. Eles propõem a igualdade de oportunidades como prioritária sobre a idéia de igualdade de participação na distribuição da riqueza produzida socialmente. Isto porque, como se sabe, os neoliberais não aceitam os preceitos que norteiam o Estado de Bem Estar Social e, principalmente, a intervenção econômica e social do Estado para abrandar as desigualdades da sociedade.

As propostas concretas de políticas sociais dos Institutos Liberais para o Brasil devem respeitar algumas determinações, entre elas: a redução do gasto público; a reorientação dos recursos para os investimentos sociais, especialmente aqueles consumidos pela população mais pobre; e a ênfase na capacitação para o trabalho para propiciar a incorporação dos mais pobres ao processo econômico (IL-RJ, p. 5, 1995). Essas determinações regem as propostas de políticas para a previdência, a saúde e a educação.

Os Institutos Liberais consideram que o sistema de previdência pública adotado no país facilita as fraudes e tende à insolvência, porque é baseado no regime de repartição, no qual os trabalhadores ativos pagam pelos benefícios que os aposentados, os doentes e os inválidos recebem, e o Estado é o gestor dos fundos. Para os neoliberais, esse sistema apresenta vários problemas. Ele é obrigatoriamente estatal, o que exige um imenso número de funcionários para administrá-lo; é responsável por políticas clientelísticas, em especial no interior; favorece as fraudes, pela ausência de registros individualizados e a impossibilidade de o contribuinte con- 
trolar sua parcela de contribuição; desestimula a poupança, uma vez que a renda futura do trabalhador estaria garantida, independente do montante de sua contribuição (IL-RJ, p. 27, 1995). Por isso a proposta apresentada pelos Institutos Liberais para a previdência baseia-se na liquidação do princípio de repartição e propõe a implantação de um sistema de capitalização.

No sistema de capitalização sob a iniciativa privada, os recursos seriam canalizados para aplicações no mercado de capitais. Esse regime estimularia o mercado de capitais e favoreceria a poupança, gerando como resultado, a longo prazo, maior eficiência na alocação de recursos. A proposta de reforma da previdência elaborada pelos liberais, baseada naquela adotada sob a ditadura do governo Pinochet no Chile, defende o sistema de capitalização, complementado pela contribuição estatal para os inválidos. Nesse sistema, a aposentadoria se dá por idade e não por tempo de serviço e apenas os trabalhadores contribuem individualmente para o fundo de pensão. Os empregadores ficam isentos da contribuição, o que, segundo o Instituto Liberal, reduziria o custo das empresas com a contratação de mão-de-obra, e, como decorrência, "produziria um substancial aumento no número de empregos" (Notas, n. 8, 1991).

Assim como no caso da previdência pública, o diagnóstico que os Institutos Liberais fazem do sistema de saúde pública no Brasil conclui que ele é ineficiente, caro, propenso a fraudes e em permanente processo de deterioração (IL-RJ, 1995). Assim como na questão da previdência, a proposta dos Institutos Liberais para solucionar os problemas da política de saúde no país visa retirar do Estado a função de prestador de serviços médicos e transferi-la para o setor privado. Segundo essa proposta, cada cidadão residente no país - independente do nível de renda - receberia do Estado um Crédito Individual de Saúde (CIS), que seria utilizado para pagamento de um plano de atendimento médico-hospitalar em uma Entidade Mantenedora de Saúde (EMS) de sua escolha. As EMS seriam instituições dedicadas exclusivamente à prestação de serviços de saúde, de origem pública ou privada. As públicas seriam aquelas que formam as redes de serviços públicos médico-hospitalares já existentes, e as privadas devem atender aos requisitos mínimos que devem ser estabelecidos com a preocupação de evitar a oligopolização do setor e as fraudes contra o sistema.

Em resumo, a proposta de reforma do sistema de saúde dos Institutos Liberais privilegia a competição entre os prestadores de serviços de saúde e prevê a universalidade de tratamento a toda a população, atribuindo ao Estado as funções de definição da regulamentação básica e de controle de qualidade dos serviços e propõe reduzir ao mínimo a regulamentação dos setores envolvidos (provedores, 
seguradores, indústria farmacêutica e organizações médicas). Esta reforma no sistema de saúde só poderá dar resultados se for complementar a outras reformas institucionais propostas pelos neoliberais para as outras áreas de políticas públicas - separação do sistema previdenciário do atendimento médico; controle da inflação; abertura do mercado de capitais; abertura do mercado nacional; abertura da área de seguradoras médicas para empresas estrangeiras; flexibilização da legislação trabalhista etc. (IL-RJ, p. 19-20, 1995)

A situação da educação no Brasil é avaliada como deficiente pelos Institutos Liberais: "a escola brasileira é cara, de baixa qualidade e dominada por um imenso corporativismo docente" (Notas, n. 1, 1990) e ainda apresenta maus rendimentos e elevados índices de analfabetismo, absenteísmo e abandono escolar. Para os liberais, a atuação do Estado na educação deve ser apenas subsidiária, concentrando-se no pré-escolar e na escola básica. (Notas, n.11, 1991). O papel do Estado deve limitar-se ao fornecimento de recursos, abandonando a prestação dos serviços de educação. Esses recursos seriam repassados aos estudantes em idade escolar em forma de um "voucher-educação", que seria trocado no mercado livre de serviços educativos. As empresas desse mercado seriam escolas privadas ou cooperativas formadas pelos professores das ex-escolas públicas, que venderiam seus serviços num regime de livre-competição. As famílias seriam os clientes, que escolheriam a escola que melhor atende às expectativas que têm sobre a educação de seus filhos. O "voucher" seria distribuído igualmente a todas as crianças em idade escolar (7 a 14 anos), independente de sua situação financeira, e ficaria a critério dos pais optar pela escola pública ou privada, acrescentando o que fosse necessário como complemento no caso de escolher a escola privada. O sistema se aplicaria em caráter universal ao primeiro grau e de forma seletiva no segundo grau, onde contemplaria apenas os alunos oriundos famílias carentes.

Quanto à educação universitária, os Institutos Liberais são contra o ensino gratuito porque, além de oneroso e ineficiente, tende a reproduzir uma situação injusta no país: a educação pública universitária acaba beneficiando os setores de mais altas rendas, oriundos do ensino elementar privado, enquanto a universidade privada, e cara, termina sendo a única possibilidade para os jovens de famílias modestas, oriundos de escolas públicas que não conseguem alcançar boa classificação no vestibular para obter vaga na Universidade pública. A proposta liberal prevê que o curso universitário seja pago pelo próprio aluno ou por financiamento em forma de bolsa de estudos, reembolsável quando concluído o curso universitário. A autonomia universitária serviria para que cada instituição pudesse dimensionar o seu corpo docente e sua capacidade de acordo com a demanda, da qual depende- 
ria seu orçamento e o custo por aluno. Os liberais imaginam que, com essa reforma, as melhores universidades aumentariam a produtividade, baixando o custo por aluno de acordo com a demanda. $\mathrm{O}$ aumento de rentabilidade deveria refletir-se nos salários dos docentes (IL-RJ, p 14, 1995).

\section{Considerações finais}

O surgimento do projeto dos Institutos Liberais no Brasil nos anos 80 deu-se numa conjuntura internacional de rearticulação das direitas, em que o capitalismo a nível mundial colocou a globalização do capital financeiro no centro do seu desenvolvimento, processo que recebeu impulso em toda a América Latina com o crescimento da dívida externa dos países, o fracasso dos planos econômicos de desenvolvimento e a imposição das políticas monetárias recessivas do FMI. Devido às características de sua economia, o Brasil conseguiu resistir por mais tempo do que outros países da região às pressões externas, mas teve que render-se aos ditames da política monetária internacional nos anos 80 . Contudo, o caso do Chile, primeiro laboratório de experimentação neoliberal na América Latina e exemplo futuro para outros projetos foi fundamental como fonte de inspiração para os neoliberais brasileiros. A leitura atenta dos projetos de reforma constitucional e de privatização da previdência apresentados pelos Institutos Liberais denunciam claramente a origem de suas formulações.

Internamente, o surgimento de uma organização político-ideológica sustentada por grandes grupos econômicos como o Instituto Liberal se explica por uma série de fatores como as mudanças econômicas em curso e os planos econômicos de estabilização e pressões do FMI, e, no campo político, a conjuntura de redemocratização, a polarização política das forças sociais, que defendiam diferentes projetos para sociedade brasileira, e a defesa dos diferentes interesses na definição do novo arcabouço institucional na Constituinte.

Como entidades civis que tomam como eixo central de sua atividade a ideologia e a difusão de uma concepção de mundo, os Institutos Liberais se propõem a difundir os valores do livre-mercado como sendo os valores da liberdade. E a pregação em defesa da liberdade se faz através da vertente mais conservadora do liberalismo - a Escola Austríaca de Economia, cujos conceitos centrais são a desigualdade natural entre os homens, o que justifica a rejeição a todas as tentativas de políticas que visem à igualdade social; a sociedade como mercado que não pode ser ordenado ou planejado; e a política como Estado Mínimo. Essa opção não nos parece casual, ela representa uma continuidade com a tradição liberal brasileira, um 
traço permanente na ideologia e nas instituições políticas, mas que sempre conviveram com a hegemonia do autoritarismo. A convivência da "lógica liberal e práxis autoritária" (Trindade, 1985) na história política brasileira mostra o quanto as elites se beneficiaram com o regime autoritário e o sistema corporativista instaurados por Vargas nos anos 30, que impôs severos limites às classes subalternas. Esses traços conservadores se confirmaram no período de transição democrática, à qual a burguesia aderiu tardiamente, e no empenho que todas as frações burguesas fizeram em defender seus interesses e impedir os avanços das classes populares no texto da nova Constituição.

É essa essência conservadora que deve explicar, enfim, a adoção dos preceitos neoliberais que regem toda a estratégia de ação e fundamentam as propostas de políticas públicas que os Institutos Liberais formulam, em especial aquelas que se referem à legislação trabalhista, e as funções sociais do Estado. As soluções propostas baseiam-se integralmente nas formulações da Escola Austríaca de Economia e são inspiradas ainda na experiência concreta de aplicação desses princípios no Chile: uma democracia limitada garantida legalmente pela Constituição, para defender a burguesia da "veleidade das massas"; a liberalização total das relações trabalhistas, a serem negociadas no "livre jogo" do mercado; e a privatização das funções sociais do Estado mais necessárias para o saneamento das desigualdades sociais tão graves num país como o Brasil: a previdência, a saúde e a educação. Esta não parece ser a tendência dominante entre as organizações mantidas por empresários no Brasil. Resta-nos observar o espaço que o Instituto Liberal conseguirá ocupar, no futuro, entre as frações empresariais e outros segmentos das elites brasileiras.

\section{Referências}

ALMEIDA, Maria Hermínia T. Crise econômica e interesses organizados: o sindicalismo no Brasil dos anos 80. São Paulo: Edusp, 1996.

ANDERSON, Perry. Balanço do neoliberalismo. In: GENTILI, Pablo; SADER, Emir (Orgs.). Pós-neoliberalismo: as políticas sociais e o Estado democrático. Rio Janeiro: Paz e Terra, 1994, p. 9-23.

CAMARGO, Aspásia; DINIZ, Eli. Dilemas da consolidação democrática no Brasil. In: (Orgs). Continuidade e mudança no Brasil da Nova República. Rio de Janeiro: Iuperj, Vértice, 1989, p. 9-17.

CARDOSO, Fernando Henrique. O papel dos empresários no processo de transição: o caso brasileiro. Dados, Rio de Janeiro, v. 26, n. 1, p. 9-27, 1983. . Autoritarismo e democratização. Rio de Janeiro: Paz e Terra, 1975.

COCKETT, Richard. Thinking the unthinkable: think-tanks and the economic counter- 
revolution 1931-1983. London: Harper Collins, 1995.

CRUZ, Sebastião C. Velasco. Empresariado e Estado na transição brasileira: um estudo sobre a economia política do autoritarismo (1974-1977). Campinas: Unicamp; São Paulo: Fapesp, 1995.

. 1977/1978: Os Empresários e a reemergência da questão social. In: O presente como história: economia e política no Brasil pós-64. Campinas: Unicamp (Coleção Trajetória, v. 3), 1997, p. 313-354.

DAVIS, Mike. The New Right's road to power. New Left Review, London, n. 128, p. 28-49, 1981.

DENHAM, Andrew. Think-tanks of the new right. England: Dartmouth Publishing, 1996.

DINIZ, Eli. Empresariado, estado e capitalismo no Brasil 1930-45. Rio de Janeiro: Paz e Terra, 1978.

Neo-liberalismo e corporativismo: as duas faces do capitalismo industrial no Brasil. In: (Org). Empresários e modernização econômica: Brasil anos 90. Florianópolis: Ufsc/Idacon, 1993, p.13-42.

DINIZ, Eli; BOSCHI, Renato. Autonomia e dependência na representação de interesses industriais. Dados, Rio de Janeiro, n. 22, 1979.

Brasil: um novo empresariado? Balanço de tendências recentes. In: DINIZ, Eli (Org). Empresários e modernização econômica: Brasil anos 90. Florianópolis: Ufsc/ Idacon, 1993, p. 113-131.

. Empresariado e estratégias de desenvolvimento: balanço e perspectivas. XXVI Encontro Anual Anpocs, Caxambu, 2002.

DOMHOFF,G. W. The Powers that be: process of ruling class domination in America. New York: Vintage Books. 1979.

DREIFUSS, René. O jogo da direita na Nova República. Petrópolis: Vozes, 1989.

GROS, Denise B. Liberalismo, empresariado e ação política na Nova República. In: DINIZ, Eli (Org.) Empresários e modernização econômica: Brasil anos 90. Florianópolis, Ufsc/ Idacon: 1993, p. 134-153.

. Institutos Liberais e neoliberalismo no Brasil da Nova República. Porto Alegre: FEE, 2003 (Teses FEE, n. 6).

HOLLINGS, Robert L. Nonprofit public policy research organizations: a sourcebook on think tanks in government. New York: Garland, 1993.

MARTINS, Luciano. Estatização da economia ou privatização do Estado? Rio de Janeiro: Paz e Terra, 1978 (Ensaios de Opinião, n. 9).

MINELLA, Ary. Banqueiros: organização e poder político no Brasil. Rio de Janeiro: Espaço e Tempo/Anpocs, 1988.

. Empresariado financeiro: organização e posicionamento no início da década de 90. In: DINIZ, Eli (Org). Empresários e modernização econômica: Brasil anos 90. Florianópolis: Ufsc/Idacon, 1993, p. 69-111.

NASH, George H. The conservative intellectual movement in America since 1945. Wilmington: Intercollegiate Studies Institute, 1996. 
RUA, Maria das Graças. A UDR e a representação de interesses dos proprietários rurais: nova elite agrária no processo de transição política no Brasil. Ciências Sociais Hoje, p. 281-310, 1990.

SCHMITTER, Philip. Still the century of corporatism? The Review of Politics, v. 36, jan. 1974.

STEFANCIC, Jean; DELGADO, Richard. No mercy: how conservative think tanks and foundations changed America's social agenda. Philadelphia: Temple University Press, 1996.

TRINDADE, Hélgio. Bases da democracia brasileira: lógica liberal e práxis autoritária (18221945). In: ROUQUIÉ, Alain et al. (Orgs.). Assim renascem as democracias. São Paulo: Brasiliense, 1985. p. 46-72.

USSEEM, Michel. The social organization of the American bussiness elite and participation of corporation directors in the governance of American institutions. American Sociological Review. v. 44, p. 553-572, ago. 1979.

VOGEL, David. The power of business in America: a re-appraisal. British Journal of Political |Science, v. 13, p.19-43, 1983.

WEAVER, Kent. The changing world of the think tanks. PS: Political Science and Politics, v. 22 , n. 3, p. 563-579, set. 1989.

\section{Publicações dos Institutos Liberais}

Idéia Liberal (IL). vários números. São Paulo: Instituto Liberal de São Paulo, 1988-1992.

Informe Liberal (IL). vários números. São Paulo: Instituto Liberal de São Paulo, 1993-1997.

IL Notícias. vários números. Rio de Janeiro: Conselho Nacional dos Institutos Liberais, 1991-1997.

Problemas sociais, soluções liberais. Rio de Janeiro: Instituto Liberal, 1995.

Notas. Avaliação de projetos de lei. vários números. Rio de Janeiro: Instituto Liberal.

Think Tank (1998-2001). São Paulo: Instituto Liberal-SP, vários números.

Texto recebido em 12.08.2003 e aprovado em 30.08.2003. 